\section{TUMOR CERVICAL POR ENFERMEDAD DE KIKUCHI}

\section{Histiocytic NeCROTIZING LYMPHADENITIS}

Sr. Editor: Mi comentario es respecto del artículo "Tumor cervical por enfermedad de Kikuchi. Una entidad clínica a la que no estamos habituados" de los Drs. $\mathrm{P}$ Gac et $\mathrm{al}^{1}$.

Considerando el extendido uso de la ecografía cervical, más aún si el paciente presenta las adenopatías propias de la enfermedad de Kikuchi, la detección concomitante de un nódulo tiroideo hace necesario considerar también al cáncer papilar de tiroides en el diagnóstico diferencial inicial, el que en gente joven puede ser especialmente agresivo en su presentación.

Esta asociación entre nódulo tiroideo y adenopatías cervicales, en todas sus posibles combinaciones (nódulo tiroideo benigno con adenopatías de otra etiología; cáncer del tiroides localizado a la glándula, con adenopatías de otro origen; cáncer del tiroides con adenopatías metastásicas), requiere la tipificación histológica del nódulo tiroideo y la detección de tiroglobulina en las adenopatías. La eventual indicación de cirugía y la extensión y oportunidad de ella dependerá de un acotado diagnóstico. Esta situación confluente de estas dos patologías se discute en el artículo publicado en 1997 en la Revista Médica de Chile, que no fue considerado en el artículo en comento ${ }^{2}$.

\section{Dr. José Manuel López M.}

Departamento de Endocrinología, Pontificia Universidad Católica de Chile, Santiago de Chile

\section{REFERENCIAS}

1. Gac P, Cabané P, Franco C, Amat J, Rossi R, Huidobro F ET AL. Tumor cervical por enfermedad de Kikuchi. Una entidad clínica a la que no estamos habituados. Caso clínico. Rev Méd Chile 2008; 136: 209-16.

2. López JM, Alvarez M, Cárdenas I, Galjegos M. Poliadenopatías cervicales por enfermedad de Kikuchi y Fujimoto. Rev Méd Chile 1997; 125: 323-7.

\section{CONSIDERACIONES AL USAR REFERENCIAS ELECTRÓNICAS DE REVISTAS IMPRESAS}

\section{CONSIDERATIONS TO USE ELECTRONIC REFERENCES FROM PRINTED JOURNALS}

Sr. Editor: En un estudio de citas biomédicas, identificamos variaciones en la forma de citar revistas que se difunden en formato impreso y electrónico (algunos ejemplos se muestran en la Tabla 1). Si bien las revistas periódicas pueden tener el formato electrónico, generalmente se acompañan de su versión impresa; y aunque ambas versiones habitualmente tienen el mismo contenido, existen revistas en las que difiere, pues pueden incluir en la versión electrónica información adicional que difícilmente saldría en la impresa (como galerías de imágenes, videos, apéndices, etc.).

El uso de la Internet brinda facilidades para acceder a fuentes de divulgación electrónica, por lo que no es correcto acceder sólo a hemerotecas para consultar información; es más, actualmente muchas de las revistas prefieren maximizar su difusión electrónica y reducir -en algunos casossu tiraje en papel, ello porque la mayoría de los lectores ubicamos los artículos en forma electrónica sin acceder en ningún momento al formato impreso de la revista ${ }^{2}$. Sin embargo, sabemos que el porcentaje de citas electrónicas es menor ${ }^{3}$, cuando técnicamente debemos citar nuestras fuentes según el modelo solicitado por la revista (en el caso de la Revista Médica de Chile, se puede diferenciar el formato de la revista consultada al colocar o no la dirección electrónica y fecha de acceso) $)^{1}$.

Por lo tanto, se debería ampliar la discusión de cuál es la forma más adecuada de citar una publicación si la revista tiene tanto el formato impreso como electrónico; por eso debemos tener presente que una cita debe ayudar a su recuperación, ser accesible y poseer el formato adecuado; además, la versión impresa puede no diferenciarse de la electrónica (en especial si accedemos a formatos PDF). Como tal, una fuente electrónica

Correspondencia a: Charles Huamaní Saldaña. Av. Arriba Perú 1154, Lima 42, Perú. Teléfono: (+51-1) 992814710. E mail: huamani_ca@hotmail.com 
Tabla 1. Formas frecuentes de citación de revistas impresas con versión electrónica*

\begin{tabular}{|c|c|c|}
\hline Característica & Forma de citación & Comentario \\
\hline $\begin{array}{l}\text { No considerar dirección } \\
\text { electrónica. }\end{array}$ & $\begin{array}{l}\text { Alarcón AM, Muñoz S. Medición en salud: } \\
\text { algunas consideraciones metodológicas. } \\
\text { Rev Med Chile. 2008; 136:125-30. }\end{array}$ & $\begin{array}{l}\text { Es la forma más frecuente pero no refleja } \\
\text { la realidad de su acceso, si la revista } \\
\text { tiene una amplia difusión electrónica su } \\
\text { recuperación sería fácil. }\end{array}$ \\
\hline $\begin{array}{l}\text { Dirección electrónica } \\
\text { de la página web. }\end{array}$ & $\begin{array}{l}\text { Alarcón AM, Muñoz S. Medición en salud: } \\
\text { algunas consideraciones metodológicas. } \\
\text { Rev Med Chile. 2008; 136:125-30. } \\
\text { Disponible en www.scielo.cl Consulta: } 31 \text { julio } 2008 .\end{array}$ & $\begin{array}{l}\text { Sólo indica que el artículo se encuentra } \\
\text { en forma electrónica, pero no ayuda } \\
\text { al usuario a una recuperación precisa } \\
\text { del artículo. }\end{array}$ \\
\hline Dirección electrónica del pdf & $\begin{array}{l}\text { Alarcón AM, Muñoz S. Medición en salud: } \\
\text { algunas consideraciones metodológicas. } \\
\text { Rev Med Chile. 2008; 136:125-30. } \\
\text { Disponible en: } \\
\text { http://www.scielo.cl/pdf/rmc/v136n1/art16.pdf } \\
\text { Consulta: } 31 \text { julio 2008. }\end{array}$ & $\begin{array}{l}\text { Aumenta la extensión de la referencia } \\
\text { y es un problema para la impresión } \\
\text { en papel. } \\
\text { A veces, la dirección se modifica en el } \\
\text { proceso de edición (tanto impreso } \\
\text { como electrónico), por lo que el } \\
\text { vínculo no es útil para el usuario. }\end{array}$ \\
\hline Dirección electrónica del html & $\begin{array}{l}\text { Alarcón AM, Muñoz S. Medición en salud: } \\
\text { algunas consideraciones metodológicas. } \\
\text { Rev Med Chile. 2008; 136:125-30. } \\
\text { Disponible en: } \\
\text { http://www.scielo.cl/scielo.php?-script=sci arttext\&pid } \\
\text { =S0034-98872008000100016\&lng=es\&nrm=iso\&tlng=es } \\
\text { Consulta: } 31 \text { julio 2008. }\end{array}$ & $\begin{array}{l}\text { Es más usado que la anterior. } \\
\text { Por lo general es más extenso } \\
\text { (especialmente para revistas en SciELO), } \\
\text { por lo que los problemas señalados son } \\
\text { mayores, además de ser poco útil para } \\
\text { lectores de la versión impresa, aún si } \\
\text { está correctamente escrita. }\end{array}$ \\
\hline $\begin{array}{l}\text { Dirección electrónica en } \\
\text { hipervínculo sobre el título } \\
\text { del artículo. }\end{array}$ & $\begin{array}{l}\text { Alarcón AM, Muñoz S. Medición en salud: } \\
\text { algunas consideraciones metodológicas. } \\
\text { Rev Med Chile. 2008; 136:125-30. }\end{array}$ & $\begin{array}{l}\text { Evita el problema del espacio en el } \\
\text { formato impreso y hace más amigable } \\
\text { y útil tanto el pdf como el html. Implica } \\
\text { un paso adicional en la edición de las } \\
\text { referencias, pero es sencillo. }\end{array}$ \\
\hline
\end{tabular}

* Se usa un mismo ejemplo para observar las variaciones en la citación, siguiendo las recomendaciones de la Revista Médica de Chile ${ }^{1}$. Se han omitido las formas diferentes de ordenamiento de "disponible en" y "consulta", así como el uso o no de (paréntesis) 0 [corchetes].

es accesible, pero no garantiza siempre una adecuada recuperación de la información ya que la dirección electrónica puede variar o desaparecer; mientras, una fuente impresa puede ser de difícil acceso, pero su archivo permite una recuperación más prolongada 4 . Por otra parte, ¿cuál sería la diferencia entre citar una fotocopia de la revista impresa o una copia impresa de la versión electrónica si ambas versiones son iguales? y para qué colocar una cita electrónica si sólo necesitamos los datos de una cita impresa para poder ubicarlo en la Internet?

No podemos esperar que todos los autores ni revisores tengan presente estas consideraciones subjetivas sobre las formas de citar una misma información. Somos los editores de revistas médicas los que debemos tener presente estas variantes y llegar a un acuerdo para uniformar criterios al citar las fuentes en nuestras revistas, para que puedan ser recuperadas y accesibles en formato electrónico e impreso (Tabla 1), ya que su repercusión no sólo podría afectar a la revista citada sino que, al conocer la naturaleza de las fuentes, facilitaríamos la gestión y adquisición de recursos documentarios ${ }^{4}$.

Por ello, recomendamos que sean las revistas las que indiquen al autor cómo citar los manuscritos que tienen ambas versiones (algunas ya lo 
hacen al colocar el aviso "citar el artículo como:..."), se debería exigir que los autores citen siempre la dirección electrónica si ambas versiones difieren y se usaron esos recursos electrónicos adicionales; que los autores mantengan la coherencia citando en forma homogénea las revistas que tengan formato impreso y electrónico y que las editoriales evalúen la factibilidad de colocar hipervínculos a las citas electrónicas, pudiendo ser éste un nuevo modelo de citación electrónica.

Finalmente, una cita electrónica o impresa teóricamente nos puede brindar información sobre la visibilidad, accesibilidad y repercusión de nuestras revistas en sus distintos formatos, pero podemos complementar esa información a través de estudios bibliométricos y de su versión electrónica a través de estudios cibermétricos.

Charles Huamaní1,3a, Percy Mayta-Tristán ${ }^{2,3}$.

${ }^{1}$ Sociedad Científica de San Fernando, Facultad de Medicina, Universidad Nacional Mayor de San Marcos. Lima, Perú.

${ }^{2}$ Revista Peruana de Medicina Experimental y Salud Pública, Instituto Nacional de Salud. Lima, Perú.

${ }^{3}$ Comité Editor, Revista Ciencia e Investigación Médica Estudiantil Latinoamericana (CIMEL). Lima, Perú.

${ }^{a}$ Estudiante de Medicina

\section{REFERENCIAS}

1. Revista Médica de Chile. Instrucciones a los autores. Disponible en: http://www.scielo.cl/revistas/rmc/ einstruc.htm. Consulta: 28 julio 2008.

2. De Groote SL, Dorsch JL Online journals: impact on print journal usage. Bull Med Libr Assoc 2001; 89: 372-8.

3. SAGUA FH. La referencia electrónica en artículos científicos. Rev Méd Chile 2007; 135: 939-41.

4. Del CastiLo-Zayas YM. Organización y representación de la información: el formato impreso y el hipertexto. ACIMED. 2006; 14 (4). Disponible en: http:// scielo.sld.cu/scielo.php?script=sci arttext\&pid=S1024-94352006000400014\&lng =es\&̄nrm=iso. Consulta: 31 julio 2008.

5. López-Piñero JM, TerRada ML. Los indicadores bibliométricos y la evaluación de la actividad médicocientífica (III). Los indicadores de producción, circulación y dispersión, consumo de la información y repercusión. Med Clin (Barc) 1992; 98: 142-8.

\section{RÉPUICA}

\section{REPLY}

C. Huamaní y P. Mayta-Tristán llaman la atención a un problema que afectaría únicamente a las citas bibliográficas de artículos publicados en revistas que tienen dos formatos: en papel y electrónico. Tal es el caso de la Revista Médica de Chile, uno de cuyos artículos recientes utilizaron como ejemplo. Esta Revista adapta sus Instrucciones a los Autores a lo recomendado por el International Committee of Medical Journal Editors (www.icmje.org) en su documento "Requisitos Uniformes para los Manuscritos Enviados a Revistas Biomédicas", el cual es actualizado aproximadamente cada dos años. Dichas recomendaciones, a su vez, adoptaron para las citas bibliográficas el sistema dispuesto por la National Library of Medicine, U.S.A., en Index Medicus (puede consultarse en National Library of Medicine's Citing Medicine).

$\mathrm{Si}$ un lector tiene acceso a una revista solamente a través de bases de datos (y no al texto impreso), dichas bases de datos dan para cada artículo su referencia bibliográfica completa. En el caso de PubMed, los artículos publicados en la Revista Médica de Chile señalan el vínculo "free full text available at SciELO.org" y ello da acceso inmediato al artículo completo. El ingreso de los artículos publicados en nuestra revista a PubMed y a SciELO es simultáneo. Por lo tanto, la loable propuesta de C. Huamaní y P. Mayta-Tristán sería útil para revistas que, publicándose en formatos impreso y electrónico, no estén indizadas en PubMed o estén solamente en bases de datos que no ofrecen "links" directos al formato electrónico.

\section{Dr. Humberto Reyes B.}

Editor, Revista Médica de Chile 